\title{
OVER DE MAKIE-DECORATIE OP DE LAKKOKER VAN HENDRICK VAN BUIJTENHEM
}

\section{'Makie' in de periode vóór de export naar Europa}

Voor een goed begrip van het makie-lakwerk op de documentenkoker van Van Buijtenhem is het noodzakelijk enige aandacht te besteden aan deze stij] en techniek en aan de oorsprong daarvan. ${ }^{1}$

Bij makie (letterlijk gesprenkelde schildering) wordt urushi of laksap gebruikt om een decoratie in goud- of zilverpoeder te laten hechten op een ondergrond. Niet alleen het goud en zilver zijn kostbaar, maar ook de lak zelf. Iedere lakboom levert immers slechts een kleine hoeveelheid urushi. Op traditionele wijze vervaardigde makie is bovendien zeer arbeidsintensief en is gemaakt door lakwerkers die eerst langdurige ervaring moesten opdoen. Om die reden werden makie-voorwerpen uitsluitend gebruikt door kleine, geprivilegieerde groepen, zoals aan het keizerlijk hof, in boeddhistische tempels en shinto heiligdommen, door de adel en door enkele krijgsheren die er een aristocratische levensstijl op na hielden.

De Japanse samenleving onderging grote veranderingen aan het eind van de $16^{\mathrm{e}}$ eeuw toen Toyotomi Hideyoshi (1536-1598) het door burgeroorlogen verscheurde land onder zich verenigde door in 1584 de laatste rivaliserende krijgsheren te verslaan. Hideyoshi maakte gebruik van makie om zijn macht tot uitdrukking te brengen. Hij liet lakwerkers wanden, plafonds, pilaren, gebruiksvoorwerpen en tafelgerei decoreren met makie, voorwerpen waarvan men tot dan toe had gemeend dat het ongepast was ze met deze kostbare technieken te decoreren. In de Kodai-ji in Kyoto, een tempel die gewijd is aan Hideyoshi en zijn echtgenote, bevinden zich verschillende meesterwerken in de makie-techniek waarvan wordt aangenomen dat ze door hen beiden zijn gebruikt. De meeste zijn in eenvoudige varianten van de techniek uitgevoerd, zoals hiramakie (vlak makie; de decoratie van goud- of zilverpoeder ligt vlak op de ondergrond), e-nashiji (een vorm van nashiji, hetgeen letterlijk perenschil betekent; bij nashiji, dat veelal voor grote vlakken, zoals de binnenkant van voorwerpen, wordt toegepast, wordt vijlsel van goud, zilver of een ander metaal of legering op de ondergrond gestrooid voor een uniforme achtergrond; bij e-nashiji wordt deze techniek voor picturale voorstellingen of motieven gebruikt) en harigaki (naaldtekening; voordat de lak gedroogd is, worden details in de decoratie geëtst met een naald). Motieven in makie, zoals emblemen van grote chrysanten of paulownia, of in vloeiende lijnen uitgevoerde herfstbloemen zijn te vinden op voorwerpen die op verschillende plaatsen in Japan bewaard zijn gebleven. Deze eenvoudige en goed herkenbare stijl wordt 'Kodai-ji makie' genoemd, naar de bovengenoemde tempel. Anders dan bij de meeste andere makie-stukken werden de motieven bij Kodai-ji makie niet eerst op het voorwerp geschetst. Soms is de plaats van de motieven in grote lijnen met rode lak op het voorwerp aangegeven, maar $2: 00: 48 \mathrm{PM}$ dikwijls volgt de uiteindelijke versiering deze lijnen niet nauwkeurig. Metee access 


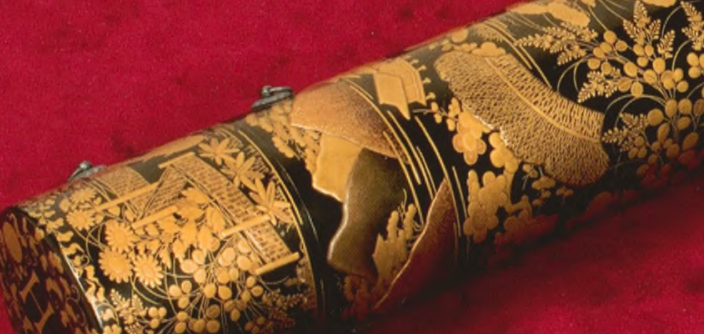

Ira 3$)^{2}=1$ c) 3 i $y^{2}$

Non?

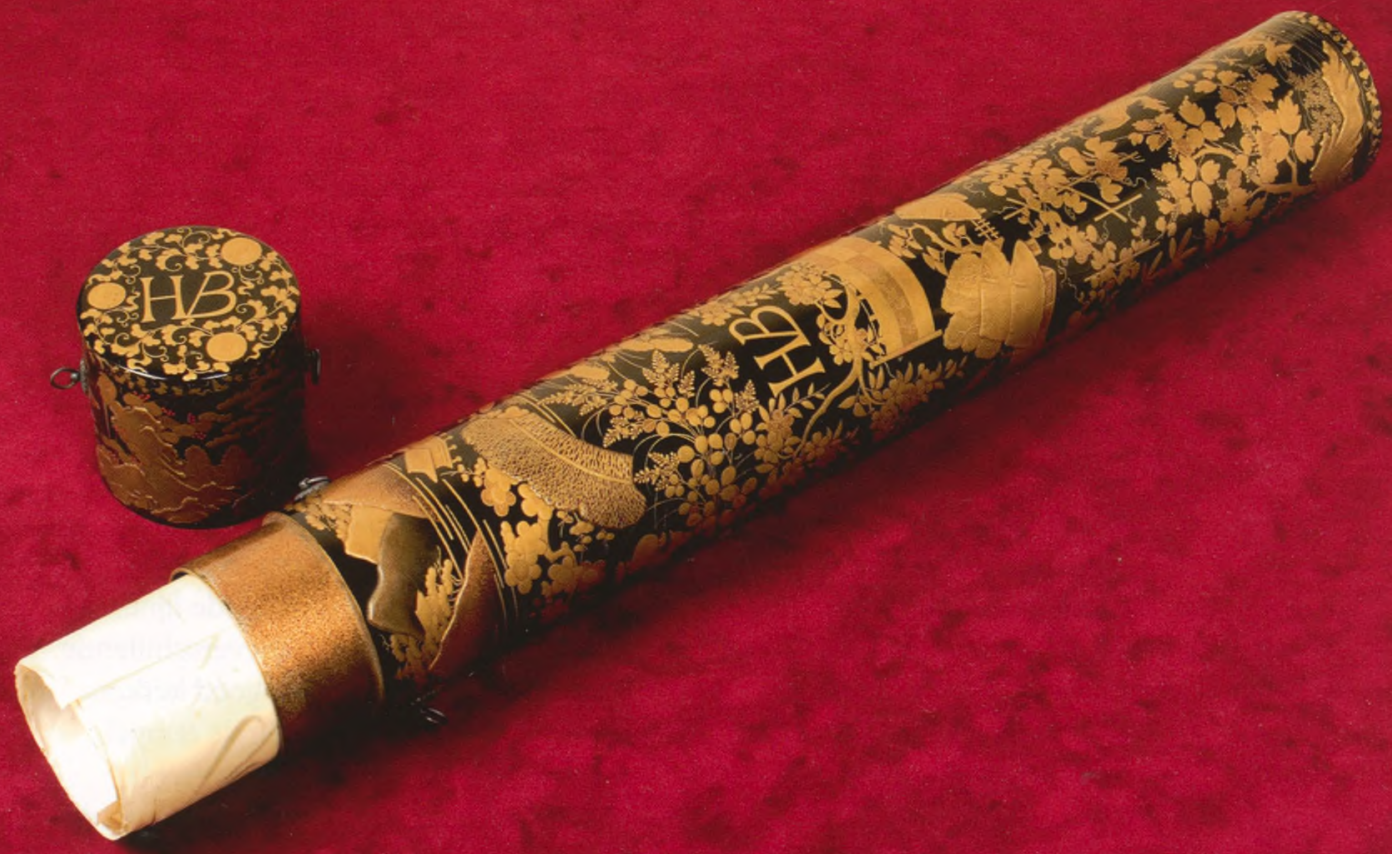




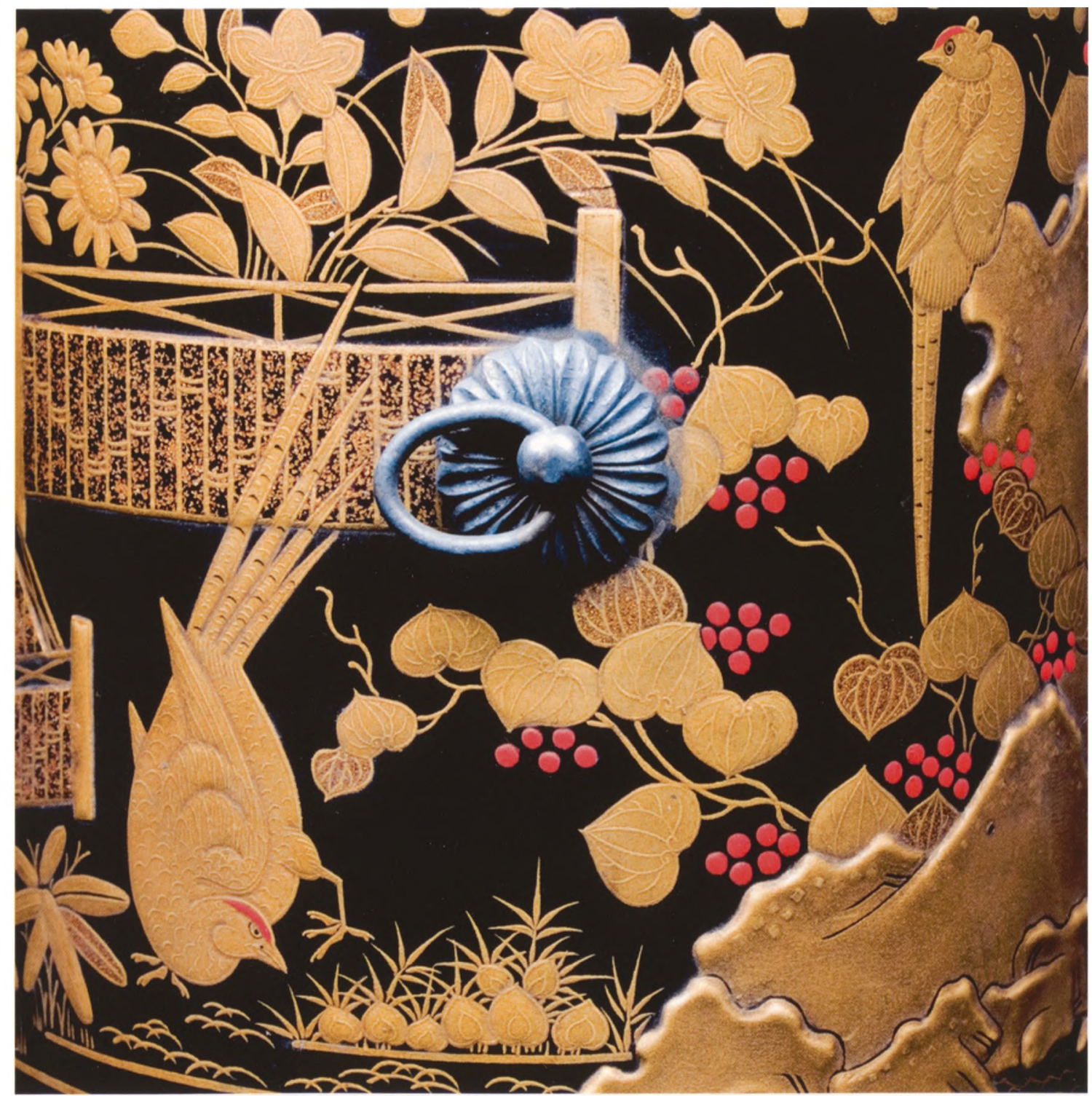

uitzondering van familiewapens werden de motieven uit de vrije hand geschilderd, wat ze een dynamische indruk geeft. In deze vrije decoraties is te zien of de lakwerker geoefend was in het schilderen met lak, hetgeen minder eenvoudig is dan schilderen in inkt.

De verandering van het regime en het economische systeem bood een aantal handwerkslieden de mogelijkheid om voor nieuwe klanten te werken: de opkomende samurai-families. Een aantal van hen waren voorheen waarschijnlijk verbonden aan het hof, of aan een heiligdom of tempel, maar werkten nu zelfstandig. Anderen waren provinciale samurai geweest die geen leider meer hadden en in Kyoto een nieuwe carrière wareen begonnenz als $_{\text {2: 00: 48p }}$ handwerksman. Dit zal ook voor de vervaardiging van makie hebberia free access 
gegolden. De vaardigheden van deze nieuwelingen waren waarschijnlijk minder dan die van bijvoorbeeld de meesters van de Koami-school, maar goed genoeg om Kodai-ji makie te maken. Sommigen van hen hadden vroeger waarschijnlijk met lak geschilderd en omdat zij gewend waren met de dikke lak op een verlakte ondergrond te werken, hoefden zij alleen te leren het goud- en zilverpoeder uit te strooien. Het ligt voor de hand dat de lakschilders geleidelijk opgingen in de groep van makie-lakwerkers. ${ }^{2}$

In deze periode arriveerden de eerste Europeanen in Japan. Men gaat er daarom van uit dat het vroegste exportlakwerk, Namban-lak (letterlijk lak voor de zuidelijke barbaren, waarmee in dit geval de Portugezen werden bedoeld), vooral door deze nieuwe groep lakwerkers werd gemaakt. Typerend voor Namban-lakwerk is de combinatie van vlakke goud-makie met parelmoer inlegwerk op een zwart verlakte ondergrond, waarbij geometrische motieven een kader vormen rond voorstellingen die het hele oppervlak bedekken. Net als bij het Kodai-ji makie werden relatief eenvoudige en goedkope technieken gebruikt om aansprekende resultaten te behalen. Ook de nashiji en harigaki technieken, bekend van het Kodai-ji makie, werden in dit Namban-lakwerk toegepast.

\section{Exportlakwerk in de $17^{\mathrm{e}}$ eeuw}

Geleidelijk aan veranderde de stijl van het exportlakwerk. ${ }^{3}$ In de jaren ' 30 en ' 40 van de $17^{\mathrm{e}}$ eeuw, toen Nederland en Portugal streden om de handel in Japan, ontwikkelden zich zowel de vormen als de decoraties. Het geometrische inlegwerk in parelmoer - een van de kenmerken van Namban-lakwerk - werd aanvankelijk vervangen door vergelijkbare motieven in hiramakie om vervolgens helemaal te verdwijnen. De decoraties met vogels en bloemen die de velden binnen de geometrische kaders vulden, maakten geleidelijk plaats voor de nieuwe mode van landschappen met paviljoens waarin grote vlakken ongedecoreerd bleven. In deze stijl werd makie in reliëf steeds meer toegepast. Dit zorgde voor een extra accent in de decoratiemotieven. Deze verandering wordt meestal verklaard vanuit een verandering in smaak van de opdrachtgevers. De Nederlanders hadden in Japan de slag met de Portugezen gewonnen en zij gaven de voorkeur aan zwart lakwerk met een gouden decor boven het Namban-lakwerk, dat de voorliefde had van de Portugezen, die ontwerpen in de Indiase stijl prefereerden. ${ }^{4}$ Onlangs is ook een financiële overweging voor deze verandering naar voren gebracht. Door een groot deel van het oppervlak ongedecoreerd te laten - in overeenstemming met de Nederlandse smaak - waren de vervaardigingkosten veel lager, ondanks de relatief dure techniek van het makie in reliëf. Zo ontwikkelden Nederlandse kooplieden en Japanse makie-lakwerkers - op zoek naar fraaie, maar toch betaalbare voorwerpen - samen een eigen, nieuwe stijl. Deze nieuwe stijl staat, ter onderscheiding van Namban-lak, bekend als Komo shikki (letterlijk 'roodharig' - dus: Nederlands - 'lakwerk').

In deze periode van overgang van Namban- naar Komo-lakwerk bestelde de Nederlandse factorij op Hirado en later op Deshima een aantal prachtige en extravagante stukken lakwerk die bedoeld waren als gift aan invloedrijke personen in andere delen van Azië, met als doel de VOC-handel te stimuleren. François Caron (1600-1673), een Fransman en hoofd van de Nederlandse factorij van 1639 tot 1641 , was waarschijnlijk betrokken bij de productie van een aantal belangrijke stukken exportlakwerk, waaronder de $_{00}$ : 48PM Van Diemen doos die zich nu in het Victoria and Albert Museum bevinde. 
Hoewel in technisch opzicht superieur, past de samengepakte decoratie binnen de ornamentele kaders in de traditie van het exportlakwerk.

Handelaren zorgden voor een ruime afzet van makie-objecten onder leden van koninklijke families in verschillende Europese landen. Na een experimentele periode in de jaren ' 30 en ' 40 van de $17^{\mathrm{e}}$ eeuw werd takamakie (makie in hoog reliëf) op een zwart verlakte achtergrond het standaard type exportlakwerk voor de daaropvolgende 100 jaar. In vrijwel elk Europees kasteel bevindt zich tenminste één kabinet in de Komo-stijl. Dit betekent dat een flink aantal werkplaatsen in Kyoto actief moet zijn geweest om aan de vraag te kunnen voldoen.

\section{De vervaardiging van 'makie' in Kyoto aan het eind van de $17^{\mathbf{e}}$ eeuw}

Engelbert Kaempfer, die Kyoto in 1691 en 1692 bezocht, heeft in zijn boek vastgelegd hoe de vervaardiging van lakwerk was georganiseerd, hoeveel werkplaatsen er waren en hoe de lakwerkers met grote vaardigheid ingewikkelde Westerse vormen kopieerden aan de hand van modellen. ${ }^{5} \mathrm{Hij}$ noemt ook lakwerk dozen en op grond van de bewaard gebleven geëxporteerde stukken uit deze periode blijkt zonneklaar dat de Europeanen in deze stad alles in makie konden bestellen wat zij begeerden.

Het is opvallend dat er zich onder het geëxporteerde lakwerk uit deze periode een grote variëteit aan vormen bevindt die niet oorspronkelijk Japans zijn. Bovendien zijn er aanwijzingen dat het opperhoofd en andere VOC-dienaren speciale opdrachten plaatsten. Onder de bewaard gebleven makie-stukken zijn schilden, dozen en borden met het familiewapen of monogram van een van de opperhoofden of van hun zaken- of persoonlijke relaties. In deze beschrijving van de makie-productie past precies de bestelling van Van Buijtenhems documenten koker. Volgens gidsen van winkels en werkplaatsen in Kyoto uit de periode 1660-1710 waren er op het moment dat de koker werd gemaakt ten minste 20 handwerkslieden die het houtwerk vervaardigden, 20 lakwerkers en 20 specialisten van makie. ${ }^{6}$

\section{Vorm en structuur van de documentenkoker}

Hoe ziet de koker er precies uit? Hij heeft een lange cilindrische vorm met een zogenaamde inro-buta sluiting (met inschietende sluitring). Aan de bovenzijde is het deksel iets bol, aan de onderzijde geheel vlak. De lengte van de koker is $68,6 \mathrm{~cm}$., de diameter $9,6 \mathrm{~cm}$. (de lengte van de koker zonder deksel is $63,9 \mathrm{~cm}$., doorsnede mond [zonder deksel] $8,9 \mathrm{~cm}$.). Op de zijkant van zowel de koker als het deksel bevinden zich - tegenover elkaar - twee ringen. De ringen zijn voorzien van kleine ronde monturen die zijn gegraveerd als chrysanten; de ring vormt de steel van de bloem. Dit is de standaardvorm voor monturen op een lakwerk doos en bood de mogelijkheid het deksel vast te knopen met behulp van een zijden koord.

De binnenzijde is eenvoudig afgewerkt met zwarte lak zoals gebruikelijk bij gewoon exportlakwerk. Onder deze zwarte lak zijn sporen van verticale lijnen te zien. Volgens de restaurator zit halverwege de koker een afgeschaafde knoop, op grond waarvan wordt verondersteld dat de basis van de koker een stuk bamboe is. Dat is goed mogelijk, aangezien andere voorbeelden bekend zijn van cilindrische voorwerpen die van bamboe zijn gemaakt, zoals een doos voor schrijfbenodigdheden gemaakt woor een krijgsheer uit het begin : $00: 48 \mathrm{PM}$ van de $17^{\mathrm{e}}$ eeuw (nu in de collectie van het Eisei-Bunko Museum). Toch' is access 
het interessant te vermelden dat een dergelijke cilinder ook gemaakt kan worden door hout te buigen, of door twee halve cilinders nauwkeurig uit een blok te snijden en met elkaar te verbinden. Deze laatste techniek is toegepast bij een pijlenkoker, gemaakt voor de Maeda-familie van de Toyama-clan (nu in het Metropolitan Museum of Art). ${ }^{7}$ De houtwerkers waren in staat (op verschillende manieren) elke gewenste vorm te maken. Röntgenonderzoek kan wellicht nog meer gegevens opleveren over de manier waarop de koker is gemaakt.

\section{'Makie'-technieken toegepast op de documentenkoker}

Het gehele oppervlak van de koker is bedekt met zwarte lak. Verder is er nashiji aangebracht aan de binnenzijde van het deksel en op de inschietende sluitring. Een effen gouden grondlaag bevindt zich op de lip van het deksel en de smalle stootrand van de koker. Voor de nashiji lijkt zilver- of tinpoeder te zijn gebruikt in plaats van goud. Dit werd dikwijls gedaan om kosten te besparen en was mogelijk omdat zowel zilver als tin onder de half doorschijnende karamelkleurige laklaag goudkleurig lijken. De gehele buitenzijde van de koker is bedekt met makie-decoraties. De gebruikte makie-technieken zijn onder te verdelen in: hiramakie; e-nashiji in twee verschillende, soms verlopende concentraties; takamakie en usuniku-takamakie (laagreliëf); kanagai (inlegwerk van uit metaalfolie gesneden elementen); kirikane (kleine stukjes gesneden goudfolie); tsukegaki (details zoals lijnen of tekeningen in goud); en geschilderde rode lak. Al deze technieken komen veelvuldig voor op lakwerk voor de binnenlandse en buitenlandse markt.

\section{Motieven}

Op de bovenzijde van het deksel en tegenover elkaar op het midden van de koker staat het monogram 'HVB' voor Hendrick van Buijtenhem (circa 16561698). Het monogram op het deksel is omgeven door arabesken waarin driemaal het chrysantenembleem is verwerkt. Dit embleem, dat tegenwoordig sterk verbonden is met de keizerlijke familie, werd ook in het verleden als iets vorstelijks gezien. Zo is bekend dat Hideyoshi dit embleem voerde met toestemming van de keizer. Het embleem werd zo algemeen toegepast dat maatregelen misbruik moesten indammen. Deze chrysanten duiden dus niet op een band met het keizerlijke hof. Arabesken sieren de bodem van de koker en de bovenste en onderste rand van de zijkanten. Het gebruik van decoratieve banden rond de voorstellingen past in de traditie van het exportlakwerk. Op de zijkant van het deksel is een hek van bamboe aangebracht met herfstbloemen zoals campanula's, chrysanten, lespedeza, en bloeiende grassen (pampagras, bamboe). Er is daar ook een poort te zien, overdekte muren en een pijnboom, rotsen met smilax (struikwinde) en een paar fazanten. Op de andere zijde bergen, een citrusboom, paviljoens, een pagode, vogels (plevieren), jonge pijnbomen met luchtwortels, wolken met ruitmotieven, een hek van gevlochten takken met een pruimenboom, huizen, een bamboehek met campanula, chrysanten, lespedeza en valerianaceae, een treurkersenboom, een bamboehek met winde, paulownia, bamboe en feniksen, rotsen met palmvarens, rozen, stromende beken, golven en een paar mandarijneenden, riet, varens, esdoorns en wilgen.

Pruimenbloesem is het symbool voor het vroege voorjaar, kersenbloesem

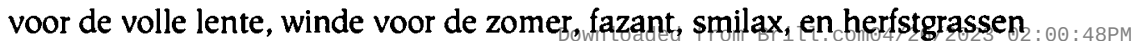
voor het najaar en de mandarijneend voor de winter. Op deze manierzijn deccess 


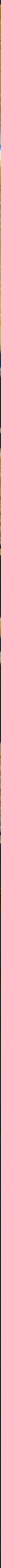



vier seizoenen op de koker weergegeven. Al deze motieven waren populair en werden in de Edo-periode veelvuldig gebruikt op kunstnijverheidproducten en op schilderingen, maar de manier waarop ze hier alle dicht opeen samen zijn gebruikt, zonder veel ongedecoreerde ruimte over te laten, is typerend voor exportkunst.

Aan sommige details is nog te zien dat de makie-werkers voortkomen uit de traditie van het schilderen met lak. De ruiten in de wolken en de lijnen in het bamboehek en de herfstbloemen zijn bijvoorbeeld hoogstwaarschijnlijk direct en zonder ondertekening op het voorwerp aangebracht. De klassieke compositie met vogels was waarschijnlijk ontleend aan een Chinees of Japans schetsboek, of zelfs aan een van de vele op dat moment beschikbare geillustreerde gedrukte boeken.

De lineaire weergave van de bladeren van de arabesken komt ook voor op de achterzijde van het deksel van de beroemde Van Diemen doos. Het is ook te vinden op het handvat van een sake-pot in de collectie van Burghley House. Deze manier van schilderen is wellicht kenmerkend voor het makie uit de werkplaatsen die voor de export produceerden. De mandarijneenden tonen grote gelijkenis met de eenden op de Van Diemen doos en met de eenden op de zeshoekige doos van Marie-Antoinette die bewaard wordt in het Musée Guimet. Het motief komt ook voor op een aantal kabinetten uit het eind van de $17^{\mathrm{e}}$ eeuw, zoals in het Kobe Municipal Museum (op dit exemplaar bevindt zich ook een fazant op een rots) en in Burghley House. Beide hebben metaalbeslag dat overeenkomt met het beslag op het kabinet in de voormalige Deense koninklijke collectie (Eac114). Aangezien het exemplaar in Denemarken al in 1674 is gedocumenteerd, kan vastgesteld worden dat deze motieven aan het eind van de $17^{\mathrm{e}}$ eeuw in de mode waren. Hoewel de kabinetten meer lege zwarte achtergrond hebben dan de koker, komen op zowel de kabinetten als de koker bomen voor met extra lijnen in goud bovenop de makie in laagreliëf.

\section{Het belang van de 'ontdekking'}

Deze koker is buitengewoon interessant, eerst en vooral vanwege het monogram en de aanstellingsbrieven. Hierdoor is bekend wie dit bijzondere makievoorwerp en wellicht ook andere speciale stukken heeft besteld. Als hij het niet zelf was, moet het iemand zijn geweest die Hendrick van Buijtenhem bijzonder dankbaar was, of iemand die bij hem in een goed blaadje wilde komen. Van belang is ook dat de koker te dateren is tussen 1684 and 1692. Door de overeenkomst van motieven en technische eigenschappen biedt dit de mogelijkheid andere, ongedateerde stukken export-makie te dateren. Als speciale bestelling is bij dit stuk meer dan gemiddelde zorg besteed aan de makie en aan de keuze van de decoraties, waardoor het ook overeenkomsten vertoont met stukken voor de binnenlandse markt. De smilax met rode vruchten naast de fazanten bijvoorbeeld, is een typerend motief in makie van de Igarashi-school. De Igarashi-school, die naar men aanneemt werkte voor het Muromachi-shogunaat in de $15^{\mathrm{e}}$ eeuw, was zeker actief in Kyoto vanaf het begin van de Edo-periode (eerste helft van de $17^{\mathrm{e}}$ eeuw). ${ }^{8}$ Deze kleine aanwijzingen kunnen ons misschien naar de werkplaatsen leiden waar deze bijzondere exportproducten werden gemaakt. Daarom is de wonderbaarlijke overlevering van deze koker, goed bewaard door verschillende generaties Nederlandse eigenaren, een schat voor de huidige onderzoekers/en 2023 02:00:48PM liefhebbers van Japanse makie. 


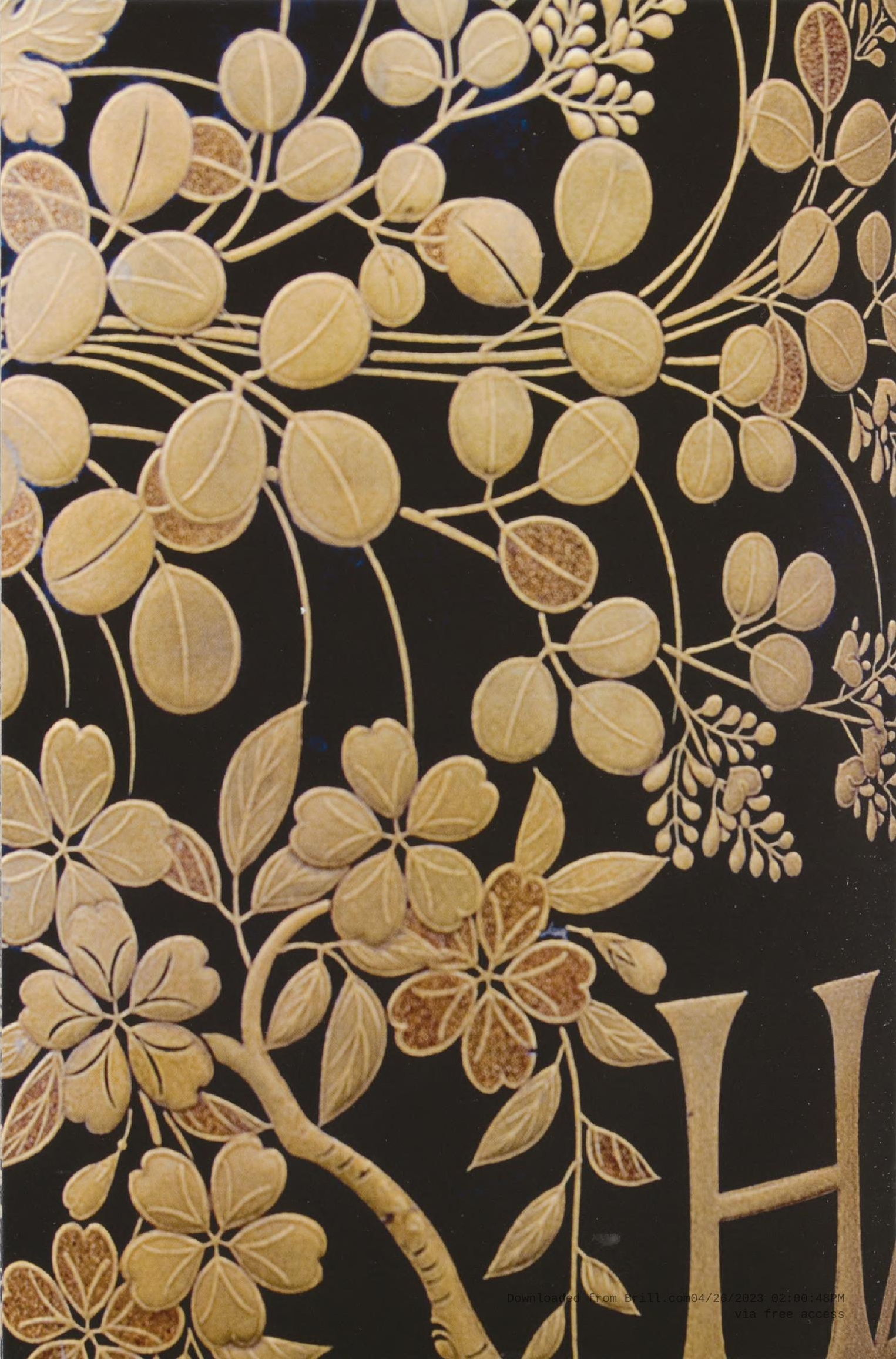


* Afbeeldingen: Fries Museum, Johan van der Veer; vertaling: Jan van Campen

1. Voor een uitgebreide versie van deze tekst, zie M. Nagashima, 'Export Lacquer: Reflection of the West in Black and Gold Makie', in: Export Lacquer: Reflection of the West in Black and Gold Makie (tentoonstellingscatalogus Kyoto National Museum), Osaka, 2008.

2. Voor meer informatie hierover, zie M. Nagashima, 'Urushi-e wan kara makie wan e: Kokura Honshu-ji zo 'Taiko-zen' no chosa hokoku oyobi Kodai-ji makie yoshiki no seiritsu to ryuko ni kansuru ichi kosatsu (A Survey of "Toyotomi Hideyoshi's" Lacquer Tableware from Honshu-ji Temple in Kokura and a Hypothesis on the Origins and Spread of the Kodai-ji Makie Style)', Gakuso 29 (2007).

3. Voor uitvoerige informatie over Japanse exportlak, zie O. Impey en C. Jörg, Japanese Export Lacquer 1580-1850, Amsterdam, 2005.

4. O. Impey, 'Japanese Export Lacquer of the 17th century', Lacquerwork in Asia and Beyond (Colloquies on Art \& Archaeology in Asia 11), Londen, 1981.

5. E. Kaempfer, The History of Japan: Together with a Description of the Kingdom of Siam, 1690-92. J. MacLehose and sons, Londen, 1906.

6. M. Nagashima, 'Mid-Edo Period Lacquer Production seen through Historical European Collections', lezing op het symposium 'Crossing Borders - The Conservation, Science and Material Culture of East Asian Lacquer', Victoria and Albert Museum, 30-31 oktober 2009.

7. S. Katsumata en K. Murose, 'Hoomon makie raden yadutsu shuri hokoku (Restoration Report on "Arrow Case with Phoenix Design in Makie")', in: Kinsei-yushutukogeihin no hozon to shufuku: Heisei 11 nendo Bunkazai Hozon Shufuku Kenkyu Kyogikai kiroku (Conservation and Restoration of Modern Export Applied Art: Record of Conference on Research for Conservation and Restoration 2000), Tokyo Kokuritsu Bunkazai Kenkyujo (National Institute for Cultural Properties, Tokyo), 2000.

8. Voor de kenmerken van de Igarashi School, zie N. Takeuchi, 'Edo-jidai zenki Igarashi-ha sakuhin ni tsuite: Maeda-ke kanren ihin wo chushin ni (Lacquer Ware of the Igarashi School from the Early Edo Period: with a focus on the works related to the Maeda family)', in: Tokyo Kokuritsu Hakubutsukan Kenkyu Kiyo 40, Tokyo National Museum, 2005. 